\title{
The ideal companion: the role of mobile phone attachment in travel purchase intention
}

Recto running head : CURRENT ISSUES IN TOURISM

Verso running head : P. RODRÍGUEZ-TORRICO ET AL.

(iD) Paula Rodríguez-Torrico, (D) Jana Prodanova, (iDSonia San-Martín, (iD Nadia Jiménez 2

Department of Economics and Business Administration, Universidad de Burgos, Burgos, Spain

CONTACT Paula Rodríguez-Torrico prtorrico@ubu.es

History : received : 2018-12-20 accepted : 2019-06-25 
Copyright Line: (c) 2019 Informa UK Limited, trading as Taylor \& Francis Group

\section{ABSTRACT}

Mobile phones have become a highly personal tool for individuals and have revolutionized many aspects of travellers' lives. Indeed, mobile phones can be considered an integral part of travellers' trip routines, thus engendering strong feelings of attachment to them. Following the stimulus-organism-response model, this paper analyses how certain stimuli (travellers' addiction to their device, perceived control, perceived entertainment, and subjective norms) influence travellers' mobile phone attachment (MPA) and intention to purchase travel using the device. The results of this model show the importance of personal and environmental factors in increasing MPA and reveal how this attachment positively influences intention toward mobile shopping for travel-related purchases. This work proposes a model in both the mobile and travel contexts with MPA as the central variable. As such, this paper contributes to the academic literature and yields several recommendations for business practice.

\section{KEYWORDS}

Attachment; mobile phone; personal; environmental; purchase; travel

\section{FUNDING}

The authors would like to thank the support provided by the Spanish Ministry of Economy and Competitiveness (ECO2017-82107$\mathrm{R})$.

\section{Introduction}

In the last two decades, mobile technologies have dramatically transformed individuals' lives. The relationship between people and this handheld technology has impacted several aspects of human behaviour, such as their consumption behaviour (Wu, Lu, Gong, \& Gupta, 2017). Considering this situation and that mobile phones accompany people wherever they go, the impact of these devices on the travel industry has been deemed as even more significant (Lamsfus, Wang, Alzua-Sorzabal, \& Xiang, 2015). Actually, different uses of these mobile devices in individuals' daily lives are associated with the way they communicate, consume information, and use their time as travellers (Wang, Xiang, \& Fesenmaier, 2016). As a result, mobile phones have changed travellers' behaviour.

Mobile phones have become digital travel assistants and are considered essential and indispensable for many travellers who refer to them as 'companion', 'secretary', 'friend', or 'safety ward' (Wang et al., 2016). For example, approximately the $80 \%$ of lastminute bookings come from mobile devices, and most travel categories (for example, activities, transportation, and accommodations) generate more than one-third of their bookings on mobile devices (Criteo, 2018). Travellers are used to having all of their travel information on their mobile phones, which is the perfect device for giving them access on the go (eDreamsOdigeo, 2017). Along with this growing trend is the development of a strong attachment of travellers to their mobile phones, to the extent that the mobile phone might even be characterized as the ideal travel companion.

Faced with this reality, firms in the tourism sector have many new opportunities to connect with travellers during all stages of the travel process (H. H. Kim \& Law, 2015). Accordingly, and in an effort to better align themselves with travellers' preferences, tourism companies have implemented several new types of mobile services (Morosan, 2014), such as mobile check-in, branded apps, free Wi-Fi access, and personalized cloud-based mobile entertainment. However, the literature lacks consumer-related studies (H. H. Kim \& Law, 2015; Liang, Schuckert, Law, \& Masiero, 2017) and, concretely, studies that address which factors stimulate customers' mobile phone attachment and its effect on mobile travel shopping.

Although research on the mobile context has experienced tremendous growth in recent years, a need still exists to better understand the bond between travellers and their mobile phones as well as how tourism firms can use this trend to offer a better shopping experience (Liang et al., 2017). In addition, the tourism context is one example in which it is essential to consider individual experiences because the consumption involves particular insight (e.g. personal stimuli) related to the travel and the destination (e.g. environmental stimuli) (Zhang, Fu, Cai, \& Lu, 2014), even more so when a mobile phone is employed in the process (Wang et al., 2016). As a result, it remains crucial to analyse the antecedents of user mobile phone attachment to understand its effects on travel shopping intentions. Therefore, this study aims to explore how mobile phone attachment (MPA), influenced by travellers' personal and environmental stimuli, affects their intention to purchase travel using their mobile phones. The data come from a sample of real online travel buyers and the stimulus-organism-response (SOR) model (Mehrabian \& Russell, 1974) is extended to better understand how people purchase their travel.

\section{Conceptual background and hypothesis development}

\section{Mobile phone attachment}

A foundational understanding of attachment is based on attachment theory (Bowlby, 1960), which was initially developed in the 
field of psychology to explain interpersonal relationships. In tourism research, the concept of attachment has been used to analyse the link between customers and physical sites, places, and destinations (Chen \& Dwyer, 2017; Qu, Xu, \& LYU, 2019) and to understand the attachment to online sites (e.g. M. J. Kim, Chung, Lee, \& Preis, 2015). The attachment between consumers and their mobile phones has only recently begun to receive attention in the marketing literature, yet focusing only on its emotional facet (Wu et al., 2017). In general, MPA is the relationship between people and their mobile phones. The relationship is characterized by a positive link and interaction between a person and his or her mobile phone (Abouzahra, Yuan, \& Tan, 2014).

To define MPA, we follow Kyle, Graefe, and Manning (2005), who treated and found support for place attachment as a secondorder construct consisting also of three dimensions: identity, dependence and social bonding. Following Kyle et al. (2005), but applying to mobile phones, the concept of MPA focuses on the phenomena of human-mobile bonding and interaction, and involves an interplay of fondness and emotions, knowledge and beliefs, and behaviours and actions.

Attending Galvagno (2011), Kyle et al. (2005) and Williams and Roggenbuck (1989), identity corresponds with the emotional symbolic meanings people ascribe to place, and dependence refers to valuing places because of their functional utility and supporting desired leisure experiences. Besides, as Kyle et al. (2005), Hidalgo and Hernandez (2001) and Raymond, Brown, and Weber (2010) stated, a third dimension, social bonding, is considered to refer to the community.

Definitively, a person will be attached to a mobile phone if: his/her self-concept is congruent with the image of the phone (identity), the mobile satisfies person's functional needs (dependence) and the person has feelings of belonging to a group if using the mobile (social bonding).

In the context of mobile shopping for travel, identity describes the emotional connection between the mobile phone and the traveller's personality. Dependence refers to the functional aspect of the attachment and reflects the functional values that the traveller gives to the characteristics and conditions of the mobile phone that support his or her goals and desired activities (Kyle et al., 2005; Williams \& Roggenbuck, 1989). Finally, social bonding represents the community or social link and it includes the activities and actions in which the traveller engages on the mobile device and incorporates other groups of people, such as family and friends, community, and even culture.

Previous literature on MPA has evolved from introducing the concept (Wehmeyer, 2007) and analysing its impact on, for example, future mobile adoption (Vincent, Haddon, \& Hamill, 2005), to analysing the impact of MPA on mobile commerce-related activities, such as consumer attitudes to mobile marketing (Rohm, Gao, Sultan, \& Pagani, 2012). More recently, MPA has been linked to the active use of short message service (Wu et al., 2017), the interpersonal attachment style (Konok, Gigler, Bereczky, \& Miklósi, 2016) and nomophobia (Han, Kim, \& Kim, 2017) However, the impact of MPA on mobile purchase intentions is still an unexplored area in the literature and, more specifically for our purposes, in the tourism context.

\section{SOR model}

The SOR model (Mehrabian \& Russell, 1974) comes from psychology and has been extensively used to understand consumers' psychological and behavioural responses toward contextual stimuli. Precisely, the model asserts that perceived stimuli generate certain reactions in people, which in turn lead to a response. When applied to the mobile purchase of travel, this model works as follows: Stimuli $(S)$ are related to travellers' personal characteristics and the mobile commerce environment. Organism (O) refers to the set of internal reactions travellers develop when perceiving the stimuli. Travellers then behave in response (R) to these internal reactions. The literature has validated the applicability of the framework for predicting traveller responses to variations of products and services (Han, 2013; Huang, Li, Mou, \& Liu, 2017; Lin \& Kuo, 2016; Loureiro, 2017; Mason \& Paggiaro, 2012; Rajaguru, 2014).

Stimulus refers to 'something that rouses or incites to action or increased action' (Sherman, Mathur, \& Smith, 1997, p. 365). Although some studies that apply the SOR model focus only on environmental inputs (Eroglu, Machleit, \& Davis, 2001; Fang, Zhao, Wen, \& Wang, 2017), the findings of previous studies indicate that both personal and environmental stimuli are essential when applying the SOR model in both the mobile (Li, Dong, \& Chen, 2012; Vazquez, Dennis, \& Zhang, 2017) and the tourism (Huang et al., 2017; Lin \& Kuo, 2016) contexts. For example, Li et al. (2012) extended the SOR framework to the mobile consumption experience including consumer inputs as stimuli. Along this line, Vazquez et al. (2017) adapted the SOR framework incorporating consumer-related variables. Therefore, to advance on new knowledge development, this research incorporates both environmental and personal cues as stimuli, offering in this way an extended version of the SOR model.

Related to the organism and according to the observation by Loureiro, Almeida, and Rita (2013), the inclusion of emotional reactions is an open question in the SOR literature. However, in addition to affective or emotional reactions, internal cognitive states are also essential for a full and adequate understanding of consumer reactions (organism) (Eroglu et al., 2001). In this sense, the literature has offered only a partial explanation of the organism activity, focusing its attention on customers' affective reactions. As stated in the previous section and with the aim of filling this gap, a more comprehensive study of the organism component is provided and considered here through the study of MPA as including identity, dependence and social bonding, 
grounding on previous literature on place and store attachment as a multidimensional construct (Galvagno, 2011; Kyle et al., 2005). In this way, the organism allows us to reach a better understanding of how individual and environmental cues can affect traveller behaviour in mobile contexts. This component of the SOR model explains the consumer reaction resulting from the stimuli, which ultimately influence consumer response - in this case, traveller intention to purchase travel using a mobile phone.

\section{Proposed model and hypotheses}

Following the SOR model, then, we identify both traveller and environmental inputs as stimuli. Mobile phone addiction and perceived controls are traveller-related stimuli and perceived entertainment, and subjective norms are factors associated with the purchasing environment. For the organism, we propose the inclusion of MPA, which will increase the mobile purchase intention, as a response. Figure 1 reflects the proposed theoretical model and our hypotheses.

Figure 1. Proposed SOR model for travel purchases.

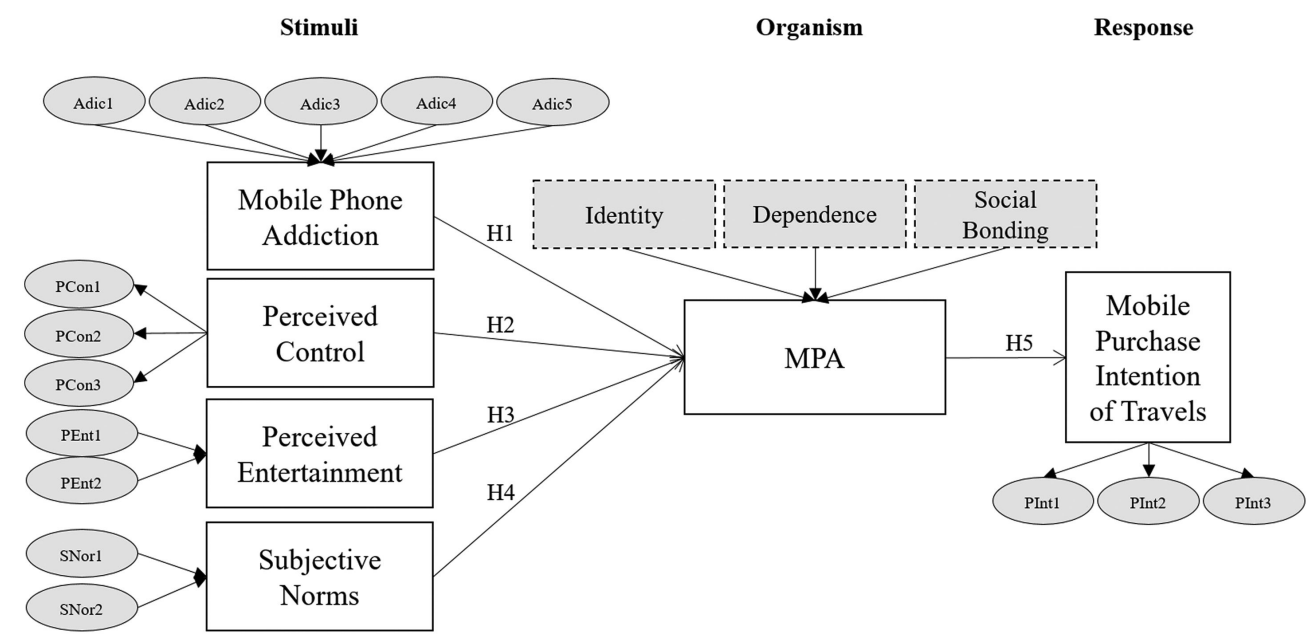

Mobile phone addiction is considered a stimulus that reflects a type of addictive behaviour resulting from repetitive mobile technology use (Park, 2005). In this sense, mobile phones are perceived as an indispensable tool that increases the user-device attachment (Wehmeyer, 2007). Accordingly, MPA is generated as a result of individuals' necessity for having and using mobile devices in their everyday lives (Abouzahra et al., 2014). In addition, the literature suggests that mobile phone addiction is positively correlated with frequent mobile phone usage and attachment (Konok et al., 2016).

In the tourism sector, given the ubiquity and connectivity of mobile phones, travellers are becoming increasingly dependent on them during their travel experiences (Tussyadiah, 2014). According to H. Han (2013), travellers' reactions also depend on personal stimuli (i.e. addiction). In addition, the use of mobile phones for accessing travel-related services is strongly connected with the intense use of these devices in everyday life (Wang et al., 2016; Wang, Xiang, \& Fesenmaier, 2014). Leaving aside the potential negative consequences of addiction, here we analyse how this stimulus can engender MPA as travellers may develop a deep emotional bond with their phones and become passionate mobile users when travelling (Tussyadiah, 2014). Therefore, we develop the following hypothesis.

H1. Mobile phone addiction positively influences travellers' MPA.

Another personal stimulus is perceived control, which refers to people's perceptions of their ability to bring about the desired behaviour (Ajzen, 1991). Research confirms that people who perceive a greater sense of control over their devices are more involved in using them (Walsh \& White, 2007) and show an increased intention to use mobile technology (Venkatesh, Thong, \& $\mathrm{Xu}$, 2012). People also identify themselves more with things over which they perceive to have greater control (Johe \& Bhullar, 2016). As such, travellers perceive mobile phones as an interrupted source of support. The development of travel apps has allowed tourists to easily use their mobile phones when travelling. As a result, they engage more in activities related to this device and develop deeper feelings of attachment to their mobile phone when travelling (Lalicic \& Weismayer, 2016). Therefore, we develop the following hypothesis.

H2. Perceived control positively influences travellers' MPA.

Prior research has confirmed that the daily live usage of mobile devices originates the same uses during travel (Wang et al., 2016). Along this line, entertainment (i.e. finding fun and enjoyment) is a determining factor of people's attitudes toward the consumption of mobile services (Cyr, Head, \& Ivanov, 2006). Consumers who have experienced enjoyment when shopping in a store develop affective bonds with and an attachment to the store (Vlachos, Theotokis, Pramatari, \& Vrechopoulos, 2010), and 
they show an increased degree of attachment to the products and the company (Schifferstein \& Zwartkruis-Pelgrim, 2008). In the tourism industry, when travellers enjoy using their mobile devices, they will be more attached to them and use them for travelling purposes (M. J.Kim, Kim, Kim, \& Kim, 2016). Consequently, we develop the following hypothesis.

H3. Perceived entertainment positively influences travellers' MPA.

Mobile phones also have a social component, which we refer to as subjective norms. These norms include a person's perception that most people who are important to him or her believe that a specific behaviour should or should not be performed (Pedersen, 2005). Mobile phones are associated with friends, family, and social connections (Vincent et al., 2005), as well as with social status and a sign of belonging to a group, all of which produce a greater sense of attachment to these devices (Wehmeyer, 2007). People tend to use mobile services to purchase travel as a result of being influenced by others (Wang et al., 2014).

Furthermore, travellers use their mobile phones to engage in various social activities, such as keeping connected with others when travelling, sharing their travel experiences, and providing information about different aspects of their trip (Wang et al., 2014). Researchers have found that the influence of others positively affects attachment to social media when travelling (Chung \& Han, 2017) and that the trust in the group also has a positive effect on attachment for online group-buyers of tourism products (M. J.Kim et al., 2015). As the final aim is to know how stimuli (subjective norms here) engenders reaction (travel mobile purchase here), we deal with the positive influence of the social group on MPA and then on purchase. Thus, we develop the following hypothesis.

H4. Subjective norms positively influence travellers' MPA,

Finally, according to previous literature (Ajzen, 1991), the intention to act, including purchase intention, derives from a positive attitude toward and a social bonding with a task. In this sense, the research has confirmed strong relationships between bonding and purchase intention (Eastlick, Lotz, \& Warrington, 2006) and between attachment and different forms of consumer behaviour (Vlachos et al., 2010). In the mobile technology context, the responses that people develop to their mobile phones are critical to the future adoption of new services related to this device (Vincent et al., 2005). The literature also treats consumer MPA as a specific construct related to mobile user behaviour (Wehmeyer, 2007; Wu et al., 2017).

This trend is likewise present in the tourism sector, where it has been shown that travellers who develop attachments to different media are more prone to use them (Chung \& Han, 2017) and to engage in mobile purchases (M. J. Kim, Chung, Lee, \& Preis, 2016). Moreover, the prior investigation has confirmed that the different uses of smartphones in everyday living determine how travellers are connected to the usage of the same device during their tourism experiences (Wang et al., 2016). Therefore, we develop the following hypothesis.

H5. MPA positively influences the intention to purchase travel using a mobile phone.

\section{Methodology}

\section{Sampling and questionnaire development}

Spain is the second European country in terms of smartphone penetration. This device is the preferred option to connect to the Internet among Spanish (Ditrendia, 2018). The data show that $41 \%$ of Spanish consumers book their travels using their mobile devices (Ditrendia, 2018). Therefore, Spanish travellers represent a suitable population from which to draw our sample.

We developed a preliminary questionnaire that employed the scales proposed and validated in the previous literature to ensure the content validity of the measures. The translation and back-translation process was completed by three Spanish-language professors who were English-speaking researchers seeking to guarantee the readability and clarity of the questionnaire (Brislin, 1980). We performed a pretest of the questionnaire with five professionals from the academic field of travel marketing and 20 experienced online travel buyers to detect and correct any deficiencies.

We then recruited 220 Spanish travel buyers, who had already made online travel-related purchases and are mobile phone users, to complete the final survey using a non-probabilistic sampling method, concretely a purposive sampling. This method is recommended when a specific predefined group is being sought (Tashakkori \& Teddlie, 2010). Accordingly, to select travellers as respondents, data were collected at bus and train stations, airports, and travel agencies. The respondents were personally interviewed after affirming a prior online travel purchase experience and expressing an intention to buy a travel arrangement using their mobile phone. Before replying to the survey, an explanation of the 'travel' concept was given to respondents to avoid misunderstanding when answering the questionnaire. Thus, it was clarified that by the term 'travel' three categories were understood: only transportation, only accommodation, or transportation and accommodation together. Moreover, it was pointed out that by 'transportation', we referred to the type of transport customers bought, including an airplane, bus, train and boat and always with a touristic purpose. 
Table 1 provides details of the sample. Its characteristics are similar to those of average Spanish online purchasers of travel, namely, young man (49.4\%) and woman (50.6\%) between 25 and 34 years of age (56.4\%), owing a graduate or postgraduate degree (20.8\%), with a monthly income above $1600 €(27.2 \%)$, who have bought travel-related services in the past 12 months (INE, 2018).

Table 1. Sample characteristics.

\begin{tabular}{|c|c|c|}
\hline Sociodemographic and economic characteristics of the sample & $\%$ & \\
\hline \multirow[t]{2}{*}{ Gender } & Male & 46.3 \\
\hline & Female & 53.7 \\
\hline \multirow[t]{6}{*}{ Age } & $18-24$ & 10.1 \\
\hline & $25-34$ & 52.3 \\
\hline & $35-44$ & 21.6 \\
\hline & $45-54$ & 12.4 \\
\hline & $55-64$ & 3.1 \\
\hline & $>64$ & 0.5 \\
\hline \multirow[t]{4}{*}{ Education } & Primary studies & 1.9 \\
\hline & High school/associate degree & 16.1 \\
\hline & University degree & 44.5 \\
\hline & Postgraduate (Master or PhD) & 37.5 \\
\hline \multirow[t]{7}{*}{ Monthly household income } & $\leq 900 €$ & 16.5 \\
\hline & $901 €-1200 €$ & 12.9 \\
\hline & $1201 €-1500 €$ & 16.1 \\
\hline & $1501 €-2000 €$ & 17.9 \\
\hline & $2001 €-3000 €$ & 18.3 \\
\hline & $3001 €-4000 €$ & 9.6 \\
\hline & $>4000 €$ & 8.7 \\
\hline \multirow[t]{4}{*}{ Purchase (times/per year) } & $1-3$ & 69.3 \\
\hline & $4-7$ & 16.5 \\
\hline & $8-10$ & 5 \\
\hline & $>10$ & 9.2 \\
\hline \multirow[t]{3}{*}{ Travel type } & Transportation & 50.4 \\
\hline & Accommodation & 17.9 \\
\hline & Both & 31.7 \\
\hline \multirow[t]{2}{*}{ Previously planned travel } & Yes & 79.4 \\
\hline & No & 20.6 \\
\hline
\end{tabular}




\section{Data analysis}

We used the partial least squares structural equation modelling (PLS-SEM) method and the statistical software SmartPLS3 to analyse the data (Bagozzi \& Yi, 2012). We followed four steps in performing this research. First, we performed a preliminary data analysis using SPSS and the two-stage SEM with SmartPLS3. Second, we ensured the unidimensionality of the scales. Third, we validated the MPA construct in the first-order measurement model and then estimated the second-order model. In both phases, we confirmed the reliability and internal consistency of the scales and convergent validity. We tested for any multicollinearity issues and then corroborated discriminant validity. Fourth, we analysed the structural model.

\section{Results}

\section{Measurement model}

We report questionnaire items and validity results in Tables 2 and 3. All items were coded on a 5-point Likert scale. To test for common method bias, we implemented Harman's single-factor test (Podsakoff, MacKenzie, Lee, \& Podsakoff, 2003). Attending Fuller, Simmering, Atinc, Atinc, and Babin (2016), Harman's One Factor Test indicates problematic common method variance if the first factor accounts for more than $50 \%$ of the variance among variables. In the exploratory factor analysis, all of the items loaded onto one factor; the unique unrotated factor explained $40.5 \%$ of the data variance. The cumulative variance explained by all of the factors in the proposed model is $80.5 \%$, thus indicating that there is no problem with common variance.

Table 2. First-order measurement model estimation.

\begin{tabular}{|c|c|c|c|}
\hline Construct & Reflective variables & Items & $\begin{array}{l}\text { Loadings } \lambda(t- \\
\text { value) }\end{array}$ \\
\hline \multirow[t]{12}{*}{ MPA } & Identity & & \\
\hline & \multirow{4}{*}{$(\alpha=.894, \mathrm{CR}=.928, \mathrm{AVE}=.763)$} & My mobile phone is part of me & .915 (79.214) \\
\hline & & I identify a lot with my mobile phone & $.922(71.435)$ \\
\hline & & I am very attached to my mobile phone & .905 (64.539) \\
\hline & & My mobile phone is very close to what I am & $.741(19.344)$ \\
\hline & \multirow{3}{*}{$\begin{array}{l}\text { Dependence }(\alpha=.876, \mathrm{CR}=.924 \\
\mathrm{AVE}=.801)\end{array}$} & $\begin{array}{l}\text { My mobile phone is the best among those of the same } \\
\text { kind }\end{array}$ & $.902(49.490)$ \\
\hline & & $\begin{array}{l}\text { Using my mobile phone satisfies me more than using any } \\
\text { other mobile phone }\end{array}$ & $.915(80.787)$ \\
\hline & & I would not change my mobile phone for another & $.867(35.342)$ \\
\hline & \multirow{4}{*}{$\begin{array}{l}\text { Social bonding }(\alpha=.836, \mathrm{CR}=.908 \\
\mathrm{AVE}=.711)\end{array}$} & My mobile phone makes me feel good & $.863(41.278)$ \\
\hline & & I have a lot of fond memories about my mobile phone & $.844(31.918)$ \\
\hline & & My mobile phone makes me happy & $.896(53.398)$ \\
\hline & & I show my mobile phone to others & .765 (18.189) \\
\hline
\end{tabular}

Table 3. Second-order measurement model estimation.

\begin{tabular}{|c|c|c|c|c|c|}
\hline Constructs & Formative variables & Weights & $t$-value & VIF & $\mathrm{TI}$ \\
\hline & $\begin{array}{l}\text { Identity (Galvagno, 2011; Kyle et al., 2005; } \\
\text { Williams \& Roggenbuck, 1989; Williams \& } \\
\text { Vaske, 2003) }\end{array}$ & .346 & 2.682 & 2.000 & .500 \\
\hline
\end{tabular}


Dependence (Galvagno, 2011; Kyle et al., 2005; Williams \& Roggenbuck, 1989; .667 $10.216 \quad 1.951 \quad .513$

Williams \& Vaske, 2003)

Social bonding (Galvagno, 2011; Kyle et al., 2005)

\begin{tabular}{|c|c|c|c|c|c|c|}
\hline \multirow{2}{*}{$\begin{array}{l}\text { Perceived entertainment (Cyr et al., } \\
\text { 2006) }\end{array}$} & $\begin{array}{l}\text { Purchasing a travel by mobile phone helps } \\
\text { me relax }\end{array}$ & .473 & 3.003 & 2.676 & .374 & \\
\hline & $\begin{array}{l}\text { Purchasing a travel by mobile phone helps } \\
\text { me entertain }\end{array}$ & .583 & 3.806 & 2.676 & .374 & \\
\hline \multirow{2}{*}{$\begin{array}{l}\text { Subjective norms (Bauer, Reichardt, } \\
\text { Barnes, \& Neumann, 2005; Shimp \& } \\
\text { Kavas, 1984) }\end{array}$} & $\begin{array}{l}\text { If I purchase a travel by mobile phone, } \\
\text { most of the people important to me } \\
\text { regard me as useful }\end{array}$ & .498 & 2.615 & 1.967 & .508 & \\
\hline & $\begin{array}{l}\text { If I purchase a travel by mobile phone, } \\
\text { most of the people important to me } \\
\text { regard it as valuable }\end{array}$ & .586 & 3.223 & 1.967 & .508 & \\
\hline \multirow{5}{*}{$\begin{array}{l}\text { Mobile phone addiction (Perse, } \\
\text { 1986; Ruiz Mafé \& Sanz Blas, 2006) }\end{array}$} & $\begin{array}{l}\text { Using my mobile phone is one of my daily } \\
\text { activities }\end{array}$ & .672 & 6.930 & 1.601 & .625 & \\
\hline & $\begin{array}{l}\text { If my mobile phone does not work, I really } \\
\text { miss it }\end{array}$ & .788 & 9.973 & 3.592 & .278 & \\
\hline & My mobile phone is important in my life & .781 & 10.435 & 3.228 & .310 & \\
\hline & $\begin{array}{l}\text { I cannot go for several days without using } \\
\text { my mobile phone }\end{array}$ & .891 & 15.518 & 2.927 & .342 & \\
\hline & I would be lost without my mobile phone & .531 & 2.709 & 2.909 & .344 & \\
\hline Constructs 1 & Reflective variables & Loadings $\lambda$ & $t$-value & AVE & CR & $\alpha$ \\
\hline \multirow{3}{*}{$\begin{array}{l}\text { Intention to purchase a travel via } \\
\text { mobile phone (Bauer et al., 2005; } \\
\text { Shimp \& Kavas, 1984) }\end{array}$} & $\begin{array}{l}\text { My general intention to purchase a travel } \\
\text { via mobile phone is very high }\end{array}$ & .934 & 74.501 & .837 & .939 & .903 \\
\hline & $\begin{array}{l}\text { I will consider purchasing a travel using a } \\
\text { mobile phone }\end{array}$ & .886 & 30.036 & & & \\
\hline & $\begin{array}{l}\text { Next time I purchase a travel, if it is } \\
\text { possible, I will do it using a mobile phone }\end{array}$ & .923 & 81.392 & & & \\
\hline \multirow{3}{*}{$\begin{array}{l}\text { Perceived control (Bauer et al., 2005; } \\
\text { Flynn \& Goldsmith, 1999) }\end{array}$} & $\begin{array}{l}\text { I have a profound knowledge of mobile } \\
\text { communications }\end{array}$ & .846 & 30.712 & .760 & .905 & .843 \\
\hline & $\begin{array}{l}\text { In comparison to my circle of friends, I am } \\
\text { an expert in mobile communications }\end{array}$ & .917 & 72.553 & & & \\
\hline & $\begin{array}{l}\text { In my circle of friends, I am usually the first } \\
\text { who knows about the latest mobile phones }\end{array}$ & .850 & 41.077 & & & \\
\hline
\end{tabular}

To specify the model, we considered two reflective latent constructs and four formative latent constructs. The construct specification has become an important issue to be considered in order to avoid assessment problems. Jarvis, MacKenzie, and Podsakoff (2003) stated, the construct misspecification could alter the conclusions about the theoretical relationships proposed in the studies. As a result, and although commonly the constructs have been viewed as reflective, it is essential to make a correct specification of the models (Jarvis et al., 2003). Following Diamantopoulos and Winklhofer (2001), a construct must be considered formative when its indicators determine it, they are not interchangeable and the omission of an indicator implies the omission of 
part of the construct; conversely, reflective indicators are determined by the construct, they are essentially interchangeable and the removal of an indicator does not change the nature of the construct. According to these characteristics, in this case, MPA, perceived entertainment, subjective norms, and mobile phone addiction are operationalized as formative constructs and intention to purchase via mobile phone and perceived control as reflective constructs.

Specifically, MPA is a formative second-order construct created from three reflective dimensions: dependence, identity, and social bonding (Kyle et al., 2005). In line with Bagozzi and Yi (2012), the inclusion of a higher-order construct (MPA) implies that the measurement assessment needs to be undertaken at two levels. Therefore, we used the two-stage approach, which has the advantage of estimating a more parsimonious model on the higher level analysis (Hair, Sarstedt, Ringle, \& Gudergan, 2018).

Thus, at the first-order level, we assessed construct validity (including internal indicator consistency), convergent validity, and discriminant validity of the measurement model (Hair et al., 2018). Consequently, we confirmed the direct relationships between dependence, identity, and social bonding dimensions and their reflective indicators, showing significant loading values ( $t>1.96$, confidence level of 95\%). Furthermore, Cronbach's alpha and composite reliability (CR) coefficients were higher than 0.7 and 0.6 (Bagozzi \& Yi, 1988), confirming the reliability and internal consistency of the scales. In addition, average variance extracted (AVE) values were higher than 0.5 in all cases (Bagozzi \& Yi, 1988). Thus, in line with the literature (Hair et al., 2018), the previously validated first-order construct (MPA) could be incorporated in the second-order measurement model. Table 2 presents the results of the first-order measurement model.

Regarding the other constructs, all weights and loading coefficients show significant values at a confidence level of 95\% ( $t>1.96$ ) for both formative and reflective latent variables, respectively. Likewise, Cronbach's alpha, CR, and AVE values confirm the reliability and validity of the reflective scales. In the case of formative constructs, the conventional methods for estimating the validity and reliability of reflective constructs are not applicable (Diamantopoulos, 1999; Diamantopoulos \& Winklhofer, 2001). An essential requirement of any model containing formative constructs is to validate that multicollinearity is not present among the formative components. Consequently, we estimated the variance inflation factor (VIF < 10) and tolerance index (TI > 0.1), allowing us to discard any notion of multicollinearity problems (Hair et al., 2018). Table 3 presents the results of the second-order measurement model.

To ensure discriminant validity between the reflective constructs, the Fornell and Larcker (1981) criterion was met, and we proceeded to confirm that AVE values for each reflective construct were greater than their squared correlations with other constructs (Table 4). Therefore, we were able to corroborate discriminant validity between the reflective constructs in the model (see Table 4). In addition, the Heterotrait-Monotrait ratio (HTMT) between the reflective variables of perceived control and intention to purchase was 0.384 (lower than 0.90), in further support of discriminant validity (Henseler, Ringle, \& Sarstedt, 2015).

Table 4. Squared correlation coefficients and AVE values.

\begin{tabular}{|l|c|c|c|c|c|c|}
\hline & ENT & IPM & MPA & PC & SN & MPADD \\
\hline ENT & - & & & & & \\
\hline IPM & .191 & .837 & & & & \\
\hline MPA & .398 & .135 & - & & & \\
\hline PC & .156 & .114 & .394 & .760 & & \\
\hline SN & .172 & .123 & .246 & .158 & - & \\
\hline MPADD & .132 & .024 & .353 & .152 & .141 & - \\
\hline
\end{tabular}

Notes: ENT: entertainment; IPM: intention to purchase travel via mobile phone; MPA: mobile phone attachment; PC: perceived control; SN: subjective norms; and MPADD: mobile phone addiction. Diagonal entries are AVE values for the reflective constructs (in bold); others are squared correlation coefficients.

\section{Structural model}

After validating the scales, we tested the proposed hypotheses by estimating the global model. The results show that all stimuli (mobile phone addiction, perceived control, perceived entertainment, and subjective norms) influence traveller MPA, thus confirming $\mathrm{H} 1, \mathrm{H} 2, \mathrm{H} 3$, and $\mathrm{H} 4$, respectively. Furthermore, in support of $\mathrm{H} 5$ (see Table 5), MPA affects consumers' intention to purchase travel using a mobile phone.

Table 5. Global model estimation. 


\begin{tabular}{|l|c|}
\hline Hypothesis & $\beta(t$-value $)$ \\
\hline H1: Mobile phone addiction $\rightarrow$ MPA & $.298(4.499)^{\star \star \star}$ \\
\hline H2: Perceived control $\rightarrow$ MPA & $.331(6.155)^{\star \star \star}$ \\
\hline H3: Perceived entertainment $\rightarrow$ MPA & $.346(5.549)^{\star \star *}$ \\
\hline H4: Subjective norms $\rightarrow$ MPA & $.110(1.974)^{\star}$ \\
\hline H5: MPA $\rightarrow$ Intention to purchase travel via mobile phone & $.368(5.310)^{\star \star \star}$ \\
\hline
\end{tabular}

${ }^{*} p<0.05,{ }^{* *} p<0.01,{ }^{* * *} p<0.001$

To determine the influence of the latent variables on the dependent constructs, we explored the changes in R-square. In accordance with Cohen (1988), small, medium, and large effect sizes are represented with the values $f^{2} \geq 0.02, f^{2} \geq 0.15$, and $f^{2} \geq$ 0.35 , respectively. The results show that subjective norms $\left(f^{2}=0.026\right)$ have a small impact on travellers' MPA, in contrast to the rest of the variables, which have larger effect sizes (perceived entertainment: $f^{2}=0.257$; perceived control: $f^{2}=0.234$; mobile phone addiction: $f^{2}=0.197$ ). Likewise, a traveller's MPA has a medium effect size in explaining the intention to purchase travel using a mobile phone $\left(f^{2}=0.156\right)$.

\section{Discussion and conclusions}

Mobile phone usage has affected different facets of people's behaviour and, concretely, their behaviour as consumers (Wu et al., 2017). Specifically, in the travel sector, travellers continuously carry and use them during the entire travel shopping process. As a result, travellers develop different degrees of attachment to their mobile device (Wang et al., 2016). This paper explores how travellers' MPA is developed and how it influences buying behaviour.

The results corroborate in the travel sector the proposals raised in the previous literature (M. J. Kim et al., 2016; Wu et al., 2017), confirming that travellers who feel MPA have greater intentions to buy using their mobile devices. Besides, the findings indicate that mobile phone addiction, perceived control, perceived entertainment, and subjective norms significantly and positively influence travellers' MPA. However, it should also be noted the minor influence of social circles' opinions (e.g. friends, family) on travellers' MPA relative to entertainment, addiction, and control.

This paper makes two main contributions to the academic field in both the tourism context and for the mobile marketing literature. First, this paper analyses MPA in not only a tourism context but also a mobile context. In contrast to previous MPA research (Rohm et al., 2012; Wu et al., 2017), this work views the MPA variable as a determinant of mobile shopping behaviour for travel. In this sense, the attachment that travellers develop to their mobile phone is crucial to understanding their intention to purchase travel. To comprehend the specific role of this variable in travellers' mobile usage behaviour, we analyse certain personal and environmental factors that increase this attachment and finally users' intention to purchase travel through their mobile devices.

Second, this work contributes to the academic literature by applying and extending the SOR model to mobile travel purchases. Academic research has mainly focused on environmental stimuli and the affective dimension of the organism construct (e.g. Fang et al., 2017), whereas this study includes both environmental and personal traveller factors as stimuli; the identity, dependence and social bonding dimensions of MPA as organism; and future mobile shopping intentions as the main consumer response. As a result, this study not only develops a model to understand the relationship between MPA and traveller behaviour intentions in mobile commerce but also fills an existing gap in both the tourism and the mobile commerce literature by adapting the SOR model for both contexts and extending it. As can be appreciated, this model offers more thorough knowledge of mobile consumer behaviour in the travel field. On this point, the present research proposes different approaches that will improve traditional theoretical models by integrating other aspects or being applied to new fields, which represents an important opportunity to advance knowledge (Crane, Henriques, Husted, \& Matten, 2016).

This study presents also managerial implications. The findings show that as users are attached to their mobile phones, they are more likely to use them as a shopping tool for travel purposes. Bearing this in mind, companies should take advantage of travellers' MPA to be useful to them when they are using their mobile phone as a shopping tool. For that end, the findings of this research offer valuable insights.

First, this study shows that travellers who experience more entertainment when buying through their mobile phone tend to develop greater MPA. It follows that, to increase travellers' MPA, companies should experiment with personalizing and differentiating their travel apps and mobile websites to promote greater entertainment through gamification - which implies the 
use of game design elements and game thinking in a non-gaming context (Deterding, Dixon, Khaled, \& Nacke, 2011).

Furthermore, travellers with greater control over the different possibilities for using the mobile device tend to perceive greater MPA. Thus, companies need to provide an attractive website or app design, easy navigation, and usable interfaces for any operative system such that travellers can feel that they are in control of the device and the processes required for mobile shopping.

Moreover, considering the importance of travellers' mobile phone addiction in MPA, companies will encourage the more intensive use of these devices if they offer ubiquitous mobile services. In this way, travellers will understand that they can use their services anytime and anywhere. As a result, firms should make an effort to offer a 360-degree travel experience (i.e. essentially becoming a mobile tourist guide for travellers). However, firms should be careful in engendering mobile addiction as it can also have negative consequences. As indicated in the literature (Turel, Serenko, \& Giles, 2011), the negative aspect of the technology addiction should not be forgotten and attention should be paid to recognize if customers' behavioural intentions would be distorted by addictions leading to withdrawal from the use of and conflict with the technology.

Lastly, firms must keep in mind that travellers' MPA is also influenced by the technological behaviour of their friends and relatives. In addition, they look to their reference groups for acknowledgment of their mobile purchase of travel. Therefore, travel apps could include a social component that would allow consumers to share their experiences with other travellers. Firms should also strengthen their use of mobile phones for travel-related services and encourage comments and word-of-mouth about their travel experiences. In doing so, companies could boost travellers' group interactions when they browse or purchase travel services. Nevertheless and taking into account that the reference groups can restrain consumer's behaviour, firms should offer the best service and travel quality to enhance positive and avoid negative comments.

Finally, this work has some limitations that should be addressed in future research. First, we considered a limited number of travellers' stimuli. Future studies might consider other variables, such as mobile convenience, consumer personality, or technology readiness. Second, the model could be extended to highlight other aspects related to a more general shopping environment and even a cross-cultural perspective, thus overcoming the limitation of being restricted to the Spanish market. Third, this study construes MPA as a second-order construct that comprises functional, emotional and social components. Further research might consider the independent effect of each dimension on the intention to purchase travel using a mobile device and, thus, enrich the knowledge about MPA effects. Finally, mainly the positive effects of engendering attachment, addiction and following subjective norms have been considered, hence in the future it would be convenient to consider the possibility of negative consequences of an intensive mobile use (i.e. addiction) and the possible restraining m-purchase behaviour (through subjective norms).

\section{Disclosure statement}

No potential conflict of interest was reported by the authors.

\section{ORCID}

Paula Rodríguez-Torrico http://orcid.org/0000-0001-9750-7104

Jana Prodanova http://orcid.org/0000-0001-6381-3621

Sonia San-Martín http://orcid.org/0000-0002-5030-9669

Nadia Jiménez http://orcid.org/0000-0001-5771-2971

\section{References}

Abouzahra, M., Yuan, Y., \& Tan, J. (2014). The role of perceived mobile device benefits and emotional attachment in enhancing the use of mobile-enabled social networks. Thirteenth Annual Workshop on HCI Research in MIS. Auckland, New Zealand.[Q5]

Ajzen, I. (1991). The theory of planned behavior. Organizational Behavior and Human Decision Processes, 50(2), $179-211$.

Bagozzi, R. P., \& Yi, Y. (1988). On the evaluation of structural equation models. Journal of the Academy of Marketing Science, 16(1), 74-94.

Bagozzi, R. P., \& Yi, Y. (2012). Specification, evaluation, and interpretation of structural equation models. Journal of the Academy of Marketing Science, 40(1), 8-34.

Bauer, H. H., Reichardt, T., Barnes, S. J., \& Neumann, M. M. (2005). Driving consumer acceptance of mobile marketing: A theoretical framework and empirical study. Journal of Electronic Commerce Research, 6(3), 181-192.

Bowlby, J. (1960). Grief and mourning in infancy and early childhood. Psychoanalytic Study of the Child, 15(1), 9-52.

Brislin, R. W. (1980). Cross-cultural research methods. In I Altman, A Rapoport, \& J F Wohlwill (Eds.), Environment and culture 
(Vol. 4, pp. 47-82). Boston, MA: Springer.

Chen, N., \& Dwyer, L. (2017). Residents' place satisfaction and place attachment on destination brand-building behaviors: Conceptual and empirical differentiation. Journal of Travel Research, 57(8), 1026-1041.

Chung, N., \& Han, H. (2017). The relationship among tourists' persuasion, attachment and behavioral changes in social media. Technological Forecasting and Social Change, 123, 370-380. Retrieved from http://www.sciencedirect.com/science/article/pii/S004016251630275X

Cohen, J. (1988). Statistical analysis for the behavioral sciences. Hillsdale: Lawrence Erlbaum.

Crane, A., Henriques, I., Husted, B. W., \& Matten, D. (2016). What constitutes a theoretical contribution in the business and society field? Business \& Society, 55(6), 783-791.

Criteo. (2018). 7 key trends for the travel industry in 2018. Retrieved from https://www.criteo.com/insights/travel-market-research/ Cyr, D., Head, M., \& Ivanov, A. (2006). Design aesthetics leading to m-loyalty in mobile commerce. Information \& Management, 43(8), 950-963. doi:10.1016/j.im.2006.08.009

Deterding, S., Dixon, D., Khaled, R., \& Nacke, L. (2011). From game design elements to gamefulness: Defining gamification. Proceedings of the 15th international academic MindTrek conference: Envisioning future media environments. Tampere, Finland.

Diamantopoulos, A. (1999). Viewpoint-export performance measurement: Reflective versus formative indicators. International Marketing Review, 16(6), 444-457.

Diamantopoulos, A., \& Winklhofer, H. M. (2001). Index construction with formative indicators: An alternative to scale development. Journal of Marketing Research, 38(2), 269-277.

Ditrendia. (2018). Informe mobile en España y en el Mundo 2018. Retrieved from https://ditrendia.es/informe-mobile-2018/

Eastlick, M. A., Lotz, S. L., \& Warrington, P. (2006). Understanding online B-to-C relationships: An integrated model of privacy concerns, trust, and commitment. Journal of Business Research, 59(8), 877-886.

eDreams-Odigeo. (2017). Dispositivos Móviles: El compañero de viaje definitivo. Retrieved from http://www.edreamsodigeo.com/wp-content/uploads/sites/19/2016/12/eDreamsODIGEO_Trends_Mobile_ESP.pdf

Eroglu, S. A., Machleit, K. A., \& Davis, L. M. (2001). Atmospheric qualities of online retailing: A conceptual model and implications. Journal of Business Research, 54(2), 177-184.

Fang, J., Zhao, Z., Wen, C., \& Wang, R. (2017). Design and performance attributes driving mobile travel application engagement. International Journal of Information Management, 37(4), 269-283.

Flynn, L. R., \& Goldsmith, R. E. (1999). A short, reliable measure of subjective knowledge. Journal of Business Research, 46(1), 5766 .

Fornell, C., \& Larcker, D. (1981). Evaluating structural equation models with unobservable variables and measurement error. Journal of Marketing Research, 18(3), 39-50. doi:10.2307/3151312

Fuller, C. M., Simmering, M. J., Atinc, G., Atinc, Y., \& Babin, B. J. (2016). Common methods variance detection in business research. Journal of Business Research, 69(8), 3192-3198.

Galvagno, M. (2011). L'attaccamento ai Luoghi Commerciali: Un'analisi Esplorativa (Store attachment: An exploratory analysis). X International Conference Marketing Trends, Paris-Venice.

Hair, J. F., Sarstedt, M., Ringle, C., \& Gudergan, S. P. (2018). Advanced issues in partial least squares structural equation modeling. Thousand Oaks, CA: Sage Publications.

Han, H. (2013). The healthcare hotel: Distinctive attributes for international medical travelers. Tourism Management, 36, $257-268$.

Han, S., Kim, K. J., \& Kim, J. H. (2017). Understanding nomophobia: Structural equation modeling and semantic network analysis of smartphone separation anxiety. Cyberpsychology, Behavior, and Social Networking, 20(7), 419-427.

Henseler, J., Ringle, C. M., \& Sarstedt, M. (2015). A new criterion for assessing discriminant validity in variance-based structural equation modeling. Journal of the Academy of Marketing Science, 43(1), 115-135.

Hidalgo, M. C., \& Hernandez, B. (2001). Place attachment: Conceptual and empirical questions. Journal of Environmental Psychology, 21(3), 273-281.

Huang, D., Li, Z., Mou, J., \& Liu, X. (2017). Effects of flow on young Chinese consumers' purchase intention: A study of eservicescape in hotel booking context. Information Technology \& Tourism, 17(2), 1-26.

Instituto Nacional de Estadística (INE). (2018). Encuesta sobre equipamiento y uso de tecnologías de información y comunicación 
en los hogares 2018. Retrieved from https://www.ine.es/dynt3/inebase/es/index.htm?padre=4803\&capsel=4805

Jarvis, C. B., MacKenzie, S. B., \& Podsakoff, P. M. (2003). A critical review of construct indicators and measurement model misspecification in marketing and consumer research. Journal of Consumer Research, 30(2), 199-218.

Johe, M. H., \& Bhullar, N. (2016). To buy or not to buy: The roles of self-identity, attitudes, perceived behavioral control and norms in organic consumerism. Ecological Economics, 128, 99-105.

Kim, M. J., Chung, N., Lee, C.-K., \& Preis, M. W. (2015). Online group-buying of tourism products: Effects of value and trust on site attachment, altruism, and loyalty. Journal of Travel \& Tourism Marketing, 32(8), 935-952.

Kim, M. J., Chung, N., Lee, C.-K., \& Preis, M. W. (2016a). Dual-route of persuasive communications in mobile tourism shopping. Telematics and Informatics, 33(2), 293-308.

Kim, M. J., Kim, W. G., Kim, J. M., \& Kim, C. (2016b). Does knowledge matter to seniors' usage of mobile devices? Focusing on motivation and attachment. International Journal of Contemporary Hospitality Management, 28(8), 1702-1727.

Kim, H. H., \& Law, R. (2015). Smartphones in tourism and Hospitality marketing: A literature review. Journal of Travel \& Tourism Marketing, 32(6), 692-711.

Konok, V., Gigler, D., Bereczky, B. M., \& Miklósi, Á. (2016). Humans' attachment to their mobile phones and its relationship with interpersonal attachment style. Computers in Human Behavior, 61, 537-547.

Kyle, G., Graefe, A., \& Manning, R. (2005). Testing the dimensionality of place attachment in recreational settings. Environment and Behavior, 37(2), 153-177.

Lalicic, L., \& Weismayer, C. (2016). The passionate use of mobiles phones among tourists. Information Technology \& Tourism, 16(2), 153-173.

Lamsfus, C., Wang, D., Alzua-Sorzabal, A., \& Xiang, Z. (2015). Going mobile defining context for on-the-go travelers. Journal of Travel Research, 54(6), 691-701.

Li, M., Dong, Z. Y., \& Chen, X. (2012). Factors influencing consumption experience of mobile commerce: A study from experiential view. Internet Research, 22(2), 120-141. doi:10.1108/10662241211214539

Liang, S., Schuckert, M., Law, R., \& Masiero, L. (2017). The relevance of mobile tourism and information technology: An analysis of recent trends and future research directions. Journal of Travel and Tourism Marketing, 34(6), 732-748.

Lin, C.-H., \& Kuo, B. Z.-L. (2016). The behavioral consequences of tourist experience. Tourism Management Perspectives, $18,84-91$. Loureiro, S. M. C. (2017). Medical tourists' emotional and cognitive response to credibility and Servicescape. Current Issues in Tourism, 20(15), 1633-1652.

Loureiro, S. M. C., Almeida, M., \& Rita, P. (2013). The effect of atmospheric cues and involvement on pleasure and relaxation: The spa hotel context. International Journal of Hospitality Management, 35, 35-43.

Mason, M. C., \& Paggiaro, A. (2012). Investigating the role of festivalscape in culinary tourism: The case of food and wine events. Tourism Management, 33(6), 1329-1336.

Mehrabian, A., \& Russell, J. A. (1974). An approach to environmental psychology. Cambridge, MA: MIT Press.

Morosan, C. (2014). Toward an integrated model of adoption of mobile phones for purchasing ancillary services in air travel. International Journal of Contemporary Hospitality Management, 26(2), 246-271.

Park, W. K. (2005). Mobile phone addiction. In Rich Ling \& Per Pedersen (Eds.), Mobile communications (Vol. 31, pp. 253-272). London: Springer.

Pedersen, P. E. (2005). Adoption of mobile internet services: An exploratory study of mobile commerce early adopters. Journal of Organizational Computing and Electronic Commerce, 15(3), 203-222.

Perse, E. M. (1986). Soap opera viewing patterns of college students and cultivation. Journal of Broadcasting \& Electronic Media, 30(2), 175-193.

Podsakoff, P. M., MacKenzie, S. B., Lee, J.-Y., \& Podsakoff, N. P. (2003). Common method biases in behavioral research: A critical review of the literature and recommended remedies. Journal of Applied Psychology, 88(5), 879-903.

Qu, Y., Xu, F., \& LYU, X. (2019). Motivational place attachment dimensions and the pro-environmental behaviour intention of mass tourists: A moderated mediation model. Current Issues in Tourism, 22(2), 197-217.

Rajaguru, R. (2014). Motion picture-induced visual, vocal and celebrity effects on tourism motivation: Stimulus organism response model. Asia Pacific Journal of Tourism Research, 19(4), 375-388.

Raymond, C. M., Brown, G., \& Weber, D. (2010). The measurement of place attachment: Personal, community, and 
environmental connections. Journal of Environmental Psychology, 30(4), 422-434.

Rohm, A. J., Gao, T. T., Sultan, F., \& Pagani, M. (2012). Brand in the hand: A cross-market investigation of consumer acceptance of mobile marketing. Business Horizons, 55(5), 485-493.

Ruiz Mafé, C., \& Sanz Blas, S. (2006). Explaining Internet dependency: An exploratory study of future purchase intention of Spanish internet users. Internet Research, 16(4), 380-397.

Schifferstein, H. N., \& Zwartkruis-Pelgrim, E. P. (2008). Consumer-product attachment: Measurement and design implications. International Journal of Design, 2(3), 1-13.

Sherman, E., Mathur, A., \& Smith, R. B. (1997). Store environment and consumer purchase behavior: Mediating role of consumer emotions. Psychology and Marketing, 14(4), 361-378.

Shimp, T. A., \& Kavas, A. (1984). The theory of reasoned action applied to coupon usage. Journal of Consumer Research, 11(3), 795-809.

Tashakkori, A., \& Teddlie, C. (2010). Sage handbook of mixed methods in social \& behavioral research. Thousand Oaks, CA: Sage.

Turel, O., Serenko, A., \& Giles, P. (2011). Integrating technology addiction and use: An empirical investigation of online auction users. Mis Quarterly, 35(4), 1043-1062.

Tussyadiah, I. P. (2014). Social actor attribution to mobile phones: The case of tourists. Information Technology \& Tourism, 14(1), 21-47.

Vazquez, D., Dennis, C., \& Zhang, Y. (2017). Understanding the effect of smart retail brand - consumer communications via mobile instant messaging (MIM) - an empirical study in the Chinese context. Computers in Human Behavior, 77, 425-436.

Venkatesh, V., Thong, J. Y., \& Xu, X. (2012). Consumer acceptance and use of information technology: Extending the unified theory of acceptance and use of technology. MIS Quarterly, 36(1), 157-178.

Vincent, J., Haddon, L., \& Hamill, L. (2005). The influence of mobile phone users on the design of $3 G$ products and services. The Journal of the Communications Network, 4(4), 69-73.

Vlachos, P. A., Theotokis, A., Pramatari, K., \& Vrechopoulos, A. (2010). Consumer-retailer emotional attachment: Some antecedents and the moderating role of attachment anxiety. European Journal of Marketing, 44(9/10), 1478-1499.

Walsh, S. P., \& White, K. M. (2007). Me, my mobile, and I: The role of self-and prototypical identity influences in the prediction of mobile phone behavior. Journal of Applied Social Psychology, 37(10), 2405-2434.

Wang, D., Xiang, Z., \& Fesenmaier, D. R. (2014). Adapting to the mobile world: A model of smartphone use. Annals of Tourism Research, 48, 11-26.

Wang, D., Xiang, Z., \& Fesenmaier, D. R. (2016). Smartphone use in everyday life and travel. Journal of Travel Research, 55(1), 5263.

Wehmeyer, K. (2007). Assessing users' attachment to their mobile devices. International conference on the management of mobile business ICMB.

Williams, D. R., \& Roggenbuck, J. W. (1989). Measuring place attachment: Some preliminary results. NRPA Symposium on Leisure Research, San Antonio, TX.

Williams, D. R., \& Vaske, J. J. (2003). The measurement of place attachment: Validity and generalizability of a psychometric approach. Forest Science, 49(6), 830-840.

Wu, T., Lu, Y., Gong, X., \& Gupta, S. (2017). A study of active usage of mobile instant messaging application: An attachment theory perspective. Information Development, 33(2), 153-168.

Zhang, H., Fu, X., Cai, L. A., \& Lu, L. (2014). Destination image and tourist loyalty: A meta-analysis. Tourism Management, 40, 213-223. 